\title{
Produções científicas do GT 16 Educação e Comunicação da ANPEd entre 2011 e 2017: contribuições da análise bibliométrica para a qualificação da área ${ }^{1}$
}

\section{Scientific productions of the GT16 Education and Communication of ANPEd between 2011 and 2017: contributions of the bibliometric analysis to the qualification of the area}

Producciones científicas del GT 16 Educación y Comunicación de la ANPEd entre 2011 y 2017: contribuciones del análisis bibliométrico para la calificación del área

Jhonny David Echalar ${ }^{2}$

Daniela da Costa Britto Pereira Lima²

Kátia Morosov Alonso ${ }^{3}$

DOI: http://dx.doi.org/10.20435/serie-estudos.v24i51.1287

\begin{abstract}
Resumo: Os dados e discussões que constituem este trabalho são oriundos de parte dos resultados de uma pesquisa em desenvolvimento cujo objetivo é compreender as perspectivas teóricas mais utilizadas nas discussões dos trabalhos aprovados no Grupo de Trabalho (GT) 16 - Educação e Comunicação, em eventos nacionais e regionais da Associação Nacional de Pesquisa em Educação (ANPEd). Para tal realizou-se o levantamento dos trabalhos disponíveis nas páginas online desses eventos, enquanto a sistematização e a análise dos dados foram alicerçadas por instrumentos das pesquisas bibliométrica e documental. O levantamento bibliográfico utilizou diferentes softwares

\footnotetext{
${ }^{1}$ Resultado parcial de pesquisa que conta com o apoio da Coordenação de Aperfeiçoamento de Pessoal de Nível Superior (Capes)/Fundação de Amparo à Pesquisa do Estado de Goiás (Fapeg) e do Conselho Nacional de Desenvolvimento Científico e Tecnológico (CNPq).

${ }^{2}$ Universidade Federal de Goiás (UFG), Goiânia, Goiás, Brasil.

${ }^{3}$ Universidade Federal de Mato Grosso, UFMT, Cuiabá, Mato Grosso, Brasil.
} 
para coleta, organização e análise dos dados, configurando-se a pesquisa como mista. Essa metodologia possibilitou observar uma maior representatividade das regiões Sul e Sudeste nos encontros nacionais, assim como um maior número de citações de autores dessas mesmas regiões nas referências analisadas. No que se refere aos encontros regionais, observa-se certa característica regionalista entre os autores-referência, mas também a inserção de outros considerados como citação indispensável, tais como Paulo Freire e Pierre Lévy, por exemplo. Em comum, os trabalhos do GT 16 utilizam mais expressivamente referências do campo da Comunicação, em relação ao da Educação, e evidenciam uma maior proximidade entre os referenciais teóricos utilizados por pesquisadores das regiões Sul e Sudeste nos encontros nacionais da Associação.

Palavras-chave: bibliometria; análise de referência; produção científica.

Abstract: The data and discussions that constitute this work are derived from part of the results of a research in development whose objective is to understand the theoretical perspectives most used in the discussions of the papers approved in the Work (GT) 16 - Education and Communication, at national and regional events of the National Association of Research in Education (ANPEd). This was done by surveying the works available on the online pages of these events, while the systematization and data analysis was based on bibliometric and documentary research tools. The bibliographic survey used different software for data collection, organization and analysis, and the research was configured as a mix. This methodology made it possible to observe a greater representation of the South and Southeast regions in the national meetings, as well as a greater number of citations from authors of these same regions in the references analyzed. As far as regional meetings are concerned, there is a certain regionalist characteristic among the authors, but also the insertion of others considered indispensable quotation, such as Paulo Freire and Pierre Lévy, for example. In common, the works of GT 16 use more expressly references of the field of Communication, in relation to that of Education, and show a greater proximity between the theoretical references used by researchers from the South and Southeast regions in the National Meetings of the Association.

Keywords: bibliometria; reference analysis; scientific production.

Resumen: Los datos y discusiones que constituyen este trabajo proceden de parte de los resultados de una investigación en desarrollo cuyo objetivo es comprender las perspectivas teóricas más utilizadas en las discusiones de los trabajos aprobados en el Grupo de trabajo (GT) 16 - Educación y Comunicación, en eventos nacionales y regionales de la Asociación Nacional de Investigación en Educación (ANPEd). Para ello se realizó el estudio de los trabajos disponibles en las páginas online de estos eventos, mientras que la sistematización y análisis de los datos fue fundada por instrumentos de las búsquedas bibliométrica y documental. La encuesta bibliográfica utilizó diferentes softwares para recopilar, organización y análisis de los datos, configurándose la investigación como mixta. Esta metodología permitió observar una mayor representatividad de las regiones Sur y Sureste en los encuentros nacionales, así como un mayor número de citas de autores de esas mismas regiones en las referencias analizadas. Por lo que se refiere a los encuentros regionales, se observa cierta característica regionalista entre los autores-referencia, pero también la inserción de otros considerados como cita indispensable, como Paulo Freire y Pierre Lévy, por ejemplo. En común, los trabajos del GT 16 utilizan más expresivamente referencias del campo de la Comunicación, en relación con el de la Educación, y evidencian una mayor proximidad entre los referenciales teóricos utilizados por investigadores de las regiones Sur y Sureste en los encuentros nacionales de la Asociación.

Palabras clave: bibliometria; análisis de referencia; producción científica. 


\section{PERCURSO DA PESQUISA}

Este estudo apresenta parte dos dados coletados em publicações dos eventos promovidos pela Associação Nacional de Pós-Graduação e Pesquisa em Educação (ANPEd) entre 2011 e 2017. Trata especificamente da análise dos autores mais recorrentes nas referências dos trabalhos publicados nos Anais das reuniões regionais e nacionais realizadas durante esse período, com o intuito de compreender as perspectivas teóricas mais utilizadas nas discussões daqueles que foram aprovados no Grupo de Trabalho (GT) 16 - Educação e Comunicação.

A motivação para observar as tendências teóricas atuais dos pesquisadores do GT 16 foi o estudo Mostafa e Máximo (2003) sobre a literatura utilizada nos grupos de trabalho que tratam da inter-relação entre comunicação e educação de duas associações científicas, a Sociedade Interdisciplinar para os Estudos da Comunicação (Intercom) e a ANPEd, no período 1998-2001. Os autores constataram que houve, naquele período, a interseção de duas correntes: o pós-estruturalismo, com base em Foucault e autores brasileiros, e os estudos críticos, com presença forte de Adorno.

Na corrente pós-estruturalista, estão presentes as categorias de gênero, saber-poder, identidade, subjetividade, sexualidade e as relações entre as esferas públicas e privadas. Entre as teorias críticas flexibilizadas, encontram-se, por exemplo, as clássicas categorias da classe social, da conscientização, alienação, emancipação, ideologia. Mas também "hegemonia" e "resistência", explorada ainda por Canclini (e demais autores latinos da Intercom que trabalharam com mediadores como família, bairro ou grupo de trabalho na produção/recepção dos produtos culturais). (MOSTAFA; MÁXIMO, 2003, p. 99).

Em uma perspectiva de análise um pouco diferenciada e voltada para a relação entre comunicação e educação, pretendeu-se, então, por meio de levantamento dos trabalhos aprovados no GT 16 da ANPEd, identificar as correntes ou tendências que fundamentaram as apreciações dos autores neles citados. Para tanto, a pesquisa da qual este artigo se origina utilizou o seguinte conjunto de softwares e sistemas operacionais para a coleta, sistematização, organização, quantificação e apresentação dos dados: NVivo - QSR International, Microsoft Excel e Microsoft Word.

Para compreender a(s) perspectiva(s) teórica(s) que constituem as reflexões dos trabalhos apresentados no GT 16 nas reuniões nacionais e regionais 
da ANPEd, fez-se necessária a aplicação de diferentes elementos de revisão bibliográfica, análise documental e levantamento bibliométrico, o que institui a pesquisa como mista, no que tange aos instrumentos de coleta, sistematização e análise de dados.

Uma revisão bibliográfica funda-se em um espectro constante de originalidade, a depender do objeto de pesquisa e dos objetivos dos pesquisadores, constituindo-se como um material opimo de informações e relevante para a transferência destas entre os pares de estudiosos do campo pesquisado (FIGUEIREDO, 1990). Conforme Vosgerau e Romanowski (2014), o número de cursos de pós-graduação e de programas de fomento à pesquisa no Brasil passa por contínua expansão, o que, consequentemente, resulta no aumento de publicações com os resultados dessas pesquisas em periódicos e eventos específicos das respectivas áreas.

Esse contexto oportuniza a realização de pesquisas, revisões e mapeamentos que apontem para perspectivas diversas, desde abordagens metodológicas a referenciais teóricos, assim como dos espaços carentes de reflexões. Ou seja, "[...] os estudos que têm por finalidade a realização desta revisão permitem a compreensão do movimento da área, sua configuração, propensões teórico-metodológicas, análise crítica, indicando tendências, recorrências e lacunas" (VOSGERAU; ROMANOWSKI, 2014, p. 167). Desse modo, a revisão realizada nos eventos do GT 16 da ANPEd constitui parte estruturante da pesquisa que dá suporte a este artigo, complementada pela realização do levantamento bibliométrico.

A bibliometria é um campo da biblioteconomia que mensura as particularidades quantitativas do conteúdo de materiais documentais definidos pelos pesquisadores como fonte de dados e que englobam artigos, livros, teses, comunicações orais, banners, atas de reuniões, Anais de eventos, dentre outros (BUFREM; PRATES, 2005). Esse tipo de pesquisa pode auxiliar a compreensão do modo como os autores mais profícuos colaboram para o desenvolvimento da área e como as correntes teóricas estão ali incorporadas.

[...] a análise das citações, de qualquer área do saber, representa o processo dinâmico, social e histórico das ligações existentes entre autores seminais e aqueles por eles influenciados, assim como das relações temáticas e institucionais explicitadas no contexto científico. Esses elementos integram-se em dimensões sociais, éticas e políticas no processo de investigação científica (BUFREM; FREITAS; NASCIMENTO, 2014, p. 151). 
A partir desses pressupostos, ressalte-se que, neste trabalho, a pesquisa bibliométrica foi aplicada para além dos indicadores estatísticos, buscando a construção de análises e relações que contribuíram para o desenvolvimento do GT 16 em seus âmbitos administrativo, teórico-metodológico, social e histórico. Tal presunção parte do entendimento de que os dados bibliométricos, além de mensurar as contribuições do conhecimento científico de determinadas áreas, podem dar suporte para a elaboração de representações históricas e atuais do campo pesquisado, auxiliando em tal construção (SOARES et al., 2016).

Neste trabalho, optou-se por apresentar os autores que possuíam no mínimo cinco recorrências nas referências. Para a definição das perspectivas teóricas e áreas de atuação, no caso de alguns autores foram realizadas buscas em seus currículos da Plataforma Lattes ${ }^{4}$, considerando, assim, informações apresentadas por eles próprios. O objetivo foi o de identificar possíveis correntes e tendências em suas produções.

O levantamento ocorreu entre outubro de 2018 e janeiro de 2019. No início, pretendeu-se realizar a busca dos trabalhos apresentados nos últimos dez anos, ou seja, entre 2007 e 2017, mas isso não foi possível, já que o acesso ao site da reunião nacional da ANPEd de 2010 não estava disponibilizado. Por esse motivo, houve um redimensionamento na busca dos dados, considerando os últimos cinco encontros nacionais (com acesso ininterrupto) e, no mesmo período, os anos em que fosse possível o acesso a todos os trabalhos de todas as regionais da associação. Nos eventos que abrangeram todas as regionais, só foi possível acesso online aos trabalhos publicados em $2014^{5}$. Nesse ano, as buscas levaram a um corpus de 132 trabalhos apresentados nas reuniões regionais, além de 95 oriundos das reuniões nacionais dos anos de 2011, 2012, 2013, 2015 e 2017. Como se pode notar, o número de trabalhos apresentados nas reuniões nacionais é inferior ao que foi registrado no único ano de reuniões regionais.

Há também de se frisar que o presente estudo não esgota, por óbvio, as possibilidades de discussão sobre correntes e tendências dos trabalhos que cir-

\footnotetext{
${ }^{4}$ A Plataforma Lattes é um sistema de informações e de integração de bases de dados de currículos, de grupos de pesquisa e de instituições, criado e mantido pelo Conselho Nacional de Desenvolvimento Científico e Tecnológico (CNPq). Disponível em: http://lattes.cnpq.br/

${ }^{5}$ São quatro os eventos regionais: Encontro de Pesquisa em Educação/Centro Oeste; Encontro de Pesquisa em Educação/Sudeste; ANPEd Sul; Encontro de Pesquisa Educacional/Norte e Nordeste.
} 
culam pelo denominado GT 16 dos eventos nacionais e regionais. Por outro lado, este levantamento não constitui uma crítica às discussões instauradas nesse âmbito, uma vez que a proposta foi apontar os referenciais teóricos que permeiam as leituras/análises desse coletivo de pesquisadores. Importante ressaltar ainda que, como não se procedeu a uma análise de conteúdo, não foram estabelecidos os temas e as categorias que dariam base aos trabalhos, o que exigiu uma investigação mais aprofundada.

Apresentam-se a seguir, respectivamente, os dados relativos às reuniões nacionais e regionais, para posterior tessitura das relações entre eles.

\section{AS REUNIÕES NACIONAIS DA ANPED E SUAS EVIDÊNCIAS}

Em primeiro lugar, deve-se ressaltar que as reuniões nacionais, nos anos em que as buscas foram realizadas, apresentaram uma concentração regional significativa, como já mencionado por Sidone, Haddad e Mena-Chalco (2016). É o que pode ser observado na Figura 1 a seguir.

Figura 1- Quantidade de trabalhos apresentados por região

$$
\because \text { SUL } ₫ \text { SUDESTE } \backsim \text { CENTRO-OESTE } \backsim \text { NORDESTE }
$$

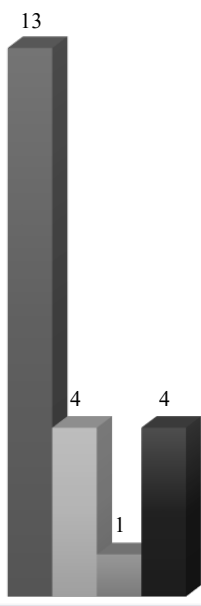

2011

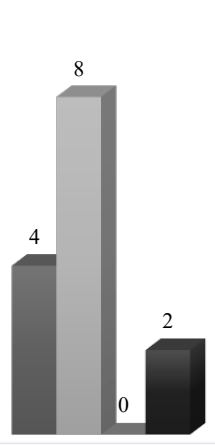

2012

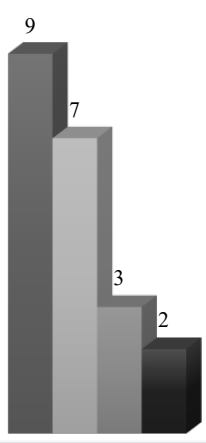

2013

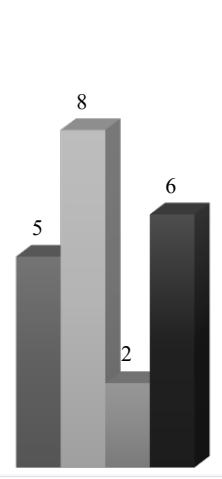

2015

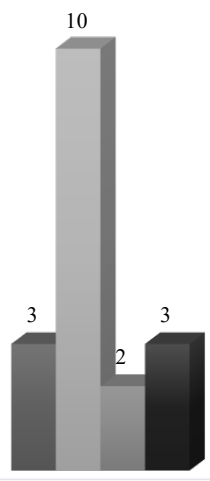

2017

Fonte: Elaborada pelos autores. 
Como evidenciado, as regiões Sul e Sudeste tiveram o maior número de trabalhos aprovados, sendo que não foram apresentados estudos da região Norte em nenhuma das reuniões, pelo menos nos anos em que ocorreram as buscas.

Uma das limitações verificadas durante o levantamento refere-se ao registro do vínculo acadêmico dos autores, tendo em vista que alguns deles se apresentaram como estudantes pós-graduandos, enquanto outros indicaram a instituição a que pertenciam. Não se pode afirmar, mas há a possibilidade de autores/coautores de trabalhos terem algum vínculo com instituições de ensino da região Norte, mas que, por razões variadas, não informem essa relação. Tal ocorrência mostra a necessidade de se ressaltar a importância da inclusão de ambos os vínculos - empregatício e acadêmico -, de modo a se preservar um retrato mais fiel da natureza da participação de pesquisadores nos GTs da ANPEd.

Os dados apontam para uma representatividade de $37 \%$ de pesquisadores da região Sudeste e de $36 \%$ da região Sul ao se quantificar o total de trabalhos levantados nas reuniões nacionais da ANPEd no interstício desta pesquisa, conforme pode ser observado na Figura 2 a seguir.

Figura 2-Representatividade regional no total de trabalhos apresentados no GT 16 nas reuniões nacionais da ANPEd

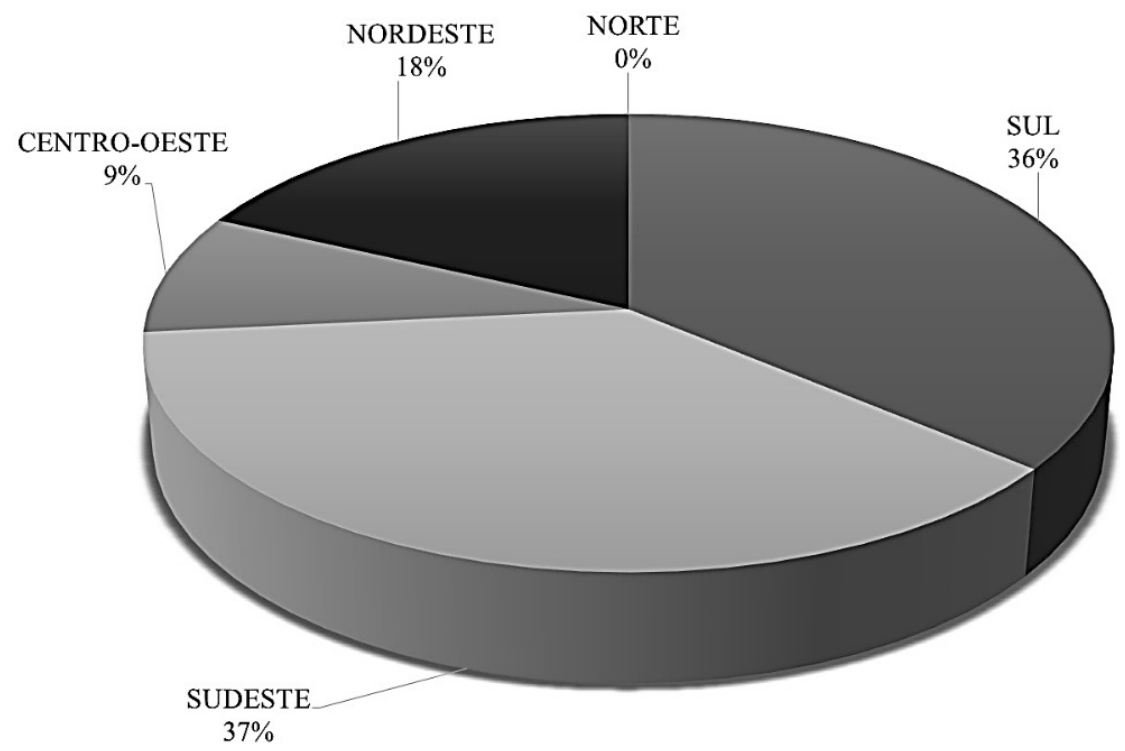

Fonte: Elaborada pelos autores. 
Com base nos resultados apresentados nas Figuras 1 e 2, é possível afirmar que o predomínio de pesquisadores do Sul e Sudeste nas reuniões nacionais da ANPEd tem a ver, é claro, com a maior quantidade de trabalhos aprovados em um ou dois eventos, o que poderia deslocar a média em favor dessas regiões. Mas é visível, na linha histórica, a maior contribuição dessas regiões no que se refere a trabalhos aprovados para discussões no GT 16.

Para a sistematização, foi feita uma busca dos autores e coautores com maior número de citações, o que resultou na identificação de 2.083 recorrências nas referências dos trabalhos pesquisados nos eventos nacionais da ANPEd. Feita a individualização de todos os autores e coautores e seu posterior agrupamento, foram quantificadas as recorrências de cada um dos citados, conforme expõe a Tabela 1.

Tabela 1- Recorrência de cada autor nos trabalhos publicados do GT 16 e apresentados em cinco reuniões nacionais da ANPEd

\begin{tabular}{|c|c|}
\hline AUTOR & RECORRÊNCIA \\
\hline LÉVY, Pierre & 35 \\
\hline FOUCAULT, Michel & 30 \\
\hline BRASIL & 28 \\
\hline LEMOS, André & 24 \\
\hline BAUMAN, Zygmunt & 23 \\
\hline BAKHTIN, Mikhail & 22 \\
\hline SANTAELLA, Lúcia & 20 \\
\hline DELEUZE, Gilles & 16 \\
\hline $\begin{array}{l}\text { COSTA, Marisa Vorraber } \\
\text { PRETTO, Nelson De Luca }\end{array}$ & 14 \\
\hline $\begin{array}{l}\text { CASTELLS, Manuel } \\
\text { GUATTARI, Félix } \\
\text { MARTÍN-BARBERO, Jesús }\end{array}$ & 13 \\
\hline FREIRE, Paulo & 12 \\
\hline BARTHES, Roland & 11 \\
\hline $\begin{array}{l}\text { FISCHER, Rosa Maria Bueno } \\
\text { SOARES, Magda Becker }\end{array}$ & 10 \\
\hline $\begin{array}{l}\text { ADORNO, Theodor Wiesengrund } \\
\text { ANDRÉ, Marli } \\
\text { BONILLA, Maria Helena Silveira } \\
\text { NÓVOA, António }\end{array}$ & 9 \\
\hline
\end{tabular}




\begin{tabular}{|c|c|}
\hline AUTOR & RECORRÊNCIA \\
\hline $\begin{array}{l}\text { HALL, Stuart } \\
\text { ROJO, Roxane } \\
\text { SANTOS, Edméa Oliveira dos }\end{array}$ & 8 \\
\hline $\begin{array}{l}\text { ALMEIDA, Maria Elizabeth } \\
\text { ARDOINO, Jacques } \\
\text { CERTEAU, Michel de } \\
\text { CHARTIER, Roger } \\
\text { FREITAS, Maria Teresa } \\
\text { HABERMAS, Jürgen } \\
\text { JENKINS, Henry } \\
\text { KASTRUP, Virgínia } \\
\text { KELLNER, Douglas } \\
\text { LARROSA, Jorge } \\
\text { MACEDO, Roberto Sidnei } \\
\text { RECUERO, Raquel } \\
\text { ROLNIK, Suely } \\
\text { TARDIF, Maurice } \\
\text { VEIGA-NETO, Alfredo } \\
\text { VYGOTSKY, Liev Semyonovich }\end{array}$ & 7 \\
\hline $\begin{array}{l}\text { BALL, Stephen John } \\
\text { BELLONI, Maria Luiza } \\
\text { BUCKINGHAM, David } \\
\text { RANCIĖRE, Jacques } \\
\text { REGO, Sheila Cristina Ribeiro } \\
\text { SIEMENS, George }\end{array}$ & 6 \\
\hline $\begin{array}{l}\text { FANTIN, Maria Eneida } \\
\text { GATTI, Bernadete } \\
\text { GIROUX, Henry } \\
\text { GOUVÊA, Guaracira } \\
\text { HORKHEIMER, Max } \\
\text { MARASCHIN, Cleci } \\
\text { MARX, Karl } \\
\text { MILL, Daniel Ribeiro Silva } \\
\text { PEIXOTO, Joana } \\
\text { PESCE, Lucila } \\
\text { PRIMO, Alex } \\
\text { SARAIVA, Karla } \\
\text { WORTMANN, Maria Lúcia Castagna }\end{array}$ & 5 \\
\hline
\end{tabular}

Fonte: Elaborada pelos autores. 
A Tabela 1 evidencia que os trabalhos aprovados no GT 16 desenvolvem uma discussão que possui maior aproximação com os referenciais teóricos do campo da Comunicação do que com o da Educação. Essa constatação já havia sido feita por Moraes (2016), ao analisar, em sua tese, os trabalhos dos pesquisadores que fundaram o GT 16. A autora, ao investigar o estado do conhecimento da relação entre educação e tecnologias, observou a existência de lacunas no que se refere a esse debate e constatou, sobretudo, que os mais citados nos trabalhos apresentados no grupo trabalhavam mais efetivamente com o campo da Filosofia e da Sociologia, e que, no campo da Educação, a presença de Paulo Freire era quase única. Moraes (2016) também chamou a atenção para a grande recorrência de trabalhos cujas fontes eram documentos governamentais, indicativo de discussões sobre as ações do Estado e de aproximação do debate com as políticas públicas.

\section{OS ENCONTROS REGIONAIS DA ANPED E SUAS DIFERENTES CONFIGURAÇÕES}

No caso dos quatro eventos regionais da ANPEd, foram adotados os mesmos procedimentos metodológicos de coleta de dados utilizados nos encontros nacionais, esclarecendo-se que pesquisadores do Norte e do Nordeste participam de uma mesma reunião. Tal metodologia gerou dados individuais de cada região, conforme consta da Tabela 2 a seguir, que reúne as recorrências de autores nos encontros regionais do ano de 2014.

Tabela 2- Recorrência de autores em cada um dos encontros regionais da ANPEd

\begin{tabular}{|c|c|c|c|c|}
\hline & $\begin{array}{c}\text { ANPEd } \\
\text { Centro-Oeste }\end{array}$ & $\begin{array}{c}\text { ANPEd } \\
\text { Norte e } \\
\text { Nordeste }\end{array}$ & $\begin{array}{c}\text { ANPEd } \\
\text { Sul }\end{array}$ & $\begin{array}{c}\text { ANPEd } \\
\text { Sudeste }\end{array}$ \\
\hline $\begin{array}{c}\text { Recorrência de } \\
\text { autores }\end{array}$ & 372 & 543 & 854 & 856 \\
\hline
\end{tabular}

Fonte: Elaborada pelos autores.

A Tabela 2 deixa evidente certa diferença entre as recorrências encontradas para os diferentes eventos regionais. Uma possível explicação para tal fato pode estar na quantidade de trabalhos enviados, o que deve influenciar o quantitativo 
daqueles que são aprovados. A se comprovar essa hipótese, haveria coincidência, portanto, entre os dados dos trabalhos apresentados nas reuniões regionais e daqueles levados à reunião nacional da ANPEd.

Percebe-se ainda que o quantitativo dos trabalhos de autores do Centro-Oeste é menor em comparação com o dos demais eventos regionais. Todavia, ao analisar os trabalhos dessa regional separadamente, identifica-se uma grande recorrência daqueles que têm origem em documentos oficiais, além de uma pulverização de autores. Ao se analisar as 372 recorrências de autores citados nos trabalhos aprovados nessa regional, apenas seis (12\%) destacaram-se com mais de cinco recorrências entre as referências, conforme pode ser visto mais adiante na Tabela 3.

No evento do Centro-Oeste, houve a inserção teórica de trabalhos do psicólogo Lev Vygotsky, proponente da Teoria Histórico-Cultural (THC), e também de um de seus seguidores, José Carlos Libâneo, pesquisador que recorre a reflexões do campo da didática para o desenvolvimento da perspectiva crítico-social dos conteúdos (LIBÂNEO, 1997). Chama também a atenção a recorrência de uma pesquisadora da mesma região, Joana Peixoto, cujo principal objeto de estudo e investigação são as relações entre as tecnologias e a educação.

Tabela 3- Recorrência de citação dos autores nas referências dos trabalhos aprovados no encontro da ANPEd Centro-Oeste do ano de 2014

\begin{tabular}{lcc}
\hline & AUTOR & CITAÇÕES \\
\hline BRASIL & 16 \\
VYGOTSKY, Lev Semyonovich & 9 \\
LÉVY, Pierre & \\
LIBÂNEO, José Carlos & 5 \\
NOGUEIRA, Maria Alice & \\
PEIXOTO, Joana & \\
\hline
\end{tabular}

Fonte: Elaborada pelos autores.

Em contraponto às produções apresentadas no evento da ANPEd do CentroOeste, o da região Sul teve 856 recorrências de autores nos trabalhos aprovados e uma menor dispersão de autores (20,6\%). Do mesmo modo, observou-se que Paulo Freire surge como referência da Educação, reforçando a importância e a inserção das reflexões freirianas nos trabalhos apresentados nessa regional (Tabela 4). 
Tabela 4 - Recorrência dos autores nas referências dos trabalhos aprovados no encontro da ANPEd - regional Sul em 2014

\begin{tabular}{lc}
\hline \multicolumn{1}{c}{ AUTORES } & CITAÇÕES \\
\hline LÉVY, Pierre & 24 \\
BRASIL & 17 \\
MATURANA, Humberto Romesin & 9 \\
FOUCAULT, Michel & \\
HALL, Stuart & \\
VARELA, Francisco José & 8 \\
DELEUZE, Gilles & 7 \\
MORIN, Edgar & \\
COSTA, Marisa Vorraber & \\
FREIRE, Paulo & \\
CASTELLS, Manuel & \\
CHARTIER, Roger & 6 \\
FISCHER, Rosa Maria Bueno & \\
HABERMAS, Jürgen & \\
PRENSKY, Marc & \\
VYGOTSKY, Lev Semyonovich & \\
BAUMAN, Zygmunt & \\
MORAN, José Manoel & \\
NÓVOA, António & \\
SANTAELLA, Lúcia & \\
SILVEIRA, Rosa Maria Hessel & \\
\hline
\end{tabular}

Fonte: Elaborada pelos autores.

A Tabela 4 apresenta dois autores nas referências que não foram encontrados com recorrências nem nas edições do evento nacional nem nas demais regionais: Humberto Maturana e Francisco Varela, que, colaborativamente, construíram a teoria da autopoiese. Tal teoria versa sobre a capacidade de os organismos vivos produzirem a si próprios e é utilizada para e nas discussões no campo dos sistemas sociais.

Observa-se, na regional Sul, a recorrência de dois filósofos também observados na região Sudeste, Michel Foucault e Gilles Deleuze. Ambos constituem ainda a maior recorrência nas reuniões nacionais da ANPEd, o que denota uma aproximação teórica entre as leituras utilizadas nas discussões daquelas duas regiões com o grupo do evento nacional. 
Entre os autores-referência nacionais que também se destacam na região Sul estão José Manoel Moran e Lúcia Santaella, oriundos da região Sudeste; e Marisa Vorraber Costa, Rosa Maria Bueno Fischer (coordenadora do GT 16 da ANPEd entre os anos de 2005 e 2006) e Rosa Maria Hessel Silveira, todas elas pesquisadoras da própria região Sul, o que ratifica a aproximação e o fluxo entre as produções dessas duas regiões. Todos esses autores trabalham os temas mídia, comunicação, pedagogias contemporâneas e literatura infantil.

No evento da ANPEd da região Sudeste, nos quais foram observadas 854 recorrências, observou-se maior diversificação quanto à quantidade de autores com cinco ou mais recorrências (25,8\%), conforme mostra a Tabela 5.

Tabela 5 - Recorrência de citação dos autores nas referências dos trabalhos aprovados no encontro da ANPEd Sudeste do ano de 2014

\begin{tabular}{|c|c|}
\hline AUTOR & CITAÇÕES \\
\hline DELEUZE, Gilles & 27 \\
\hline FREIRE, Paulo & 24 \\
\hline ALMEIDA, Maria Elizabeth Bianconcini & 19 \\
\hline GUATTARI, Félix & 18 \\
\hline FOUCAULT, Michel & 14 \\
\hline BARBOSA, Ana Mae & 13 \\
\hline $\begin{array}{l}\text { BRASIL } \\
\text { LARROSA, Jorge }\end{array}$ & 10 \\
\hline ADORNO, Theodor Wiesengrund & 9 \\
\hline BAUMAN, Zygmunt & 8 \\
\hline $\begin{array}{l}\text { LEMOS, André } \\
\text { MORIN, Edgar } \\
\text { VALENTE, José Armando }\end{array}$ & 7 \\
\hline $\begin{array}{l}\text { BAKHTIN, Mikhail } \\
\text { DUARTE, Rosália }\end{array}$ & 6 \\
\hline $\begin{array}{l}\text { BENJAMIN, Walter } \\
\text { CANEVACCI, Massimo } \\
\text { FERNANDES, Adriana Hoffmann } \\
\text { FREITAS, Maria Teresa de Assunção } \\
\text { LÉVY, Pierre } \\
\text { LUKÁCS, György } \\
\text { SANTAELLA, Lúcia }\end{array}$ & 5 \\
\hline
\end{tabular}

Fonte: Elaborada pelos autores. 
No que tange aos autores com maior recorrência nas pesquisas da região Sudeste, destacam-se o filósofo Gilles Deleuze e o psicanalista Félix Guattari. Tal incidência ocorre pelo fato de os dois terem escrito seis obras em conjunto, que tratam de temas como política, cultura e psicanálise. O filósofo Michel Foucault também tem menção expressiva entre as referências, como já observado nas reuniões nacionais da associação.

Ao se analisar os autores brasileiros de maior recorrência no Sudeste, constata-se que oito deles são oriundos da própria região: Paulo Freire, Maria Elizabeth Bianconcini Almeida, Ana Mae Barbosa, José Armando Valente, Rosália Duarte, Adriana Hoffmann Fernandes, Maria Teresa de Assunção Freitas e Lúcia Santaella, sendo que suas áreas de atuação contemplam tecnologias e educação, arte e educação e comunicação. Cabe ressaltar a atuação de Maria Elizabeth Bianconcini Almeida e José Armando Valente, como pesquisadores de tecnologia e educação vinculados ao MEC, e a de Adriana Hoffmann Fernandes, como parecerista ad hoc na ANPEd e no GT 16, em 2011 e 2012, e como vice-coordenadora em 2013 e coordenadora deste GT entre 2014 e 2015.

Como já observado para região Centro-Oeste, nas reuniões da regional Norte/Nordeste, observa-se grande recorrência de referências a documentos oficiais, seguindo-se as de Paulo Freire, o mesmo ocorrendo nos encontros nacionais. Das 543 recorrências de autores citados, 20,6\% estão entre os cinco mais recorrentes (Tabela 6). 
Tabela 6 - Recorrência de citação de autores nas referências dos trabalhos aprovados no encontro da ANPEd - regional Norte/Nordeste de 2014

\begin{tabular}{|c|c|}
\hline AUTOR & CITAÇÕES \\
\hline BRASIL & 21 \\
\hline FREIRE, Paulo & 9 \\
\hline $\begin{array}{l}\text { CASTELLS, Manuel } \\
\text { LÉVY, Pierre } \\
\text { MACEDO, Roberto Sidnei }\end{array}$ & 8 \\
\hline $\begin{array}{l}\text { KENSKI, Vani Moreira } \\
\text { STREET, Brian }\end{array}$ & 7 \\
\hline $\begin{array}{l}\text { BELLONI, Maria Luiza } \\
\text { HABERMAS, Jürgen } \\
\text { LACLAU, Ernesto } \\
\text { MORIN, Edgar }\end{array}$ & 6 \\
\hline $\begin{array}{l}\text { BALL, Stephen John } \\
\text { PETERS, Otto } \\
\text { PRETTO, Nelson De Luca } \\
\text { VYGOTSKY, Lev Semyonovich }\end{array}$ & 5 \\
\hline
\end{tabular}

Fonte: Elaborada pelos autores.

Assim como nos dados dos eventos nacionais, é possível observar que os autores Manuel Castells e Pierre Lévy também estão entre os que possuem maior recorrência nas referências dos trabalhos da regional Norte/Nordeste. Chama também a atenção a inserção da pesquisadora Vani Moreira Kenski entre os autores com maior recorrência nas referências das pesquisas dessas regiões.

Outro que atua nessa linha de tecnologia e educação e que surge nos dados da regional Norte/Nordeste é o professor Nelson De Luca Pretto, docente da Universidade Federal da Bahia (UFBA). Ele desenvolve pesquisas sobre a relação entre educação e comunicação, educação e cibercultura, educação a distância e informática educativa. Ainda nessa perspectiva, emerge dos dados a inserção nas referências da professora Maria Luiza Belloni, que já atuou como membro e coordenadora do GT 16 e esteve vinculada, até sua aposentadoria, à Universidade Federal de Santa Catarina (UFSC). Também entre os autores-referência brasileiros do GT 16 está o professor Roberto Sidnei Macedo, com vínculo ao GT de currículo. 


\section{OS EVENTOS NACIONAIS E REGIONAIS DA ANPED: EM BUSCA DE SÍNTESES}

A análise, em conjunto, dos dados gerais obtidos tanto nas reuniões nacionais quanto nas regionais da ANPEd evidencia a inserção dos diferentes autores nas discussões das diferentes esferas desta pesquisa. Nesse sentido, aponta-se para a grande recorrência de documentos emanados da União em ambas as bases de dados, o que aponta para discussões relacionadas às políticas públicas em âmbito nacional e à constituição desses documentos como objeto de análise dos trabalhos apresentados.

Tabela 7 - Recorrência geral de cada autor, a partir das referências bibliográficas dos trabalhos aprovados nos encontros nacionais e regionais da ANPEd

\begin{tabular}{|c|c|c|c|}
\hline \multicolumn{2}{|l|}{ NACIONAL } & \multicolumn{2}{|l|}{ REGIONAIS } \\
\hline AUTOR & RECORRÊNCIA & AUTOR & RECORRÊNCIA \\
\hline LÉVY, Pierre & 35 & BRASIL & 64 \\
\hline FOUCAULT, Michel & 30 & LÉVY, Pierre & 42 \\
\hline BRASIL & 28 & FREIRE, Paulo & 40 \\
\hline LEMOS, André & 24 & DELEUZE, Gilles & 35 \\
\hline BAUMAN, Zygmunt & 23 & FOUCAULT, Michel & 23 \\
\hline BAKHTIN, Mikhail & 22 & MORIN, Edgar & 21 \\
\hline SANTAELLA, Lúcia & 20 & VYGOTSKY, Lev Semyonovich & 20 \\
\hline DELEUZE, Gilles & 16 & $\begin{array}{l}\text { ALMEIDA, Maria Elizabeth } \\
\text { Bianconcini de }\end{array}$ & 19 \\
\hline $\begin{array}{l}\text { COSTA, Marisa Vorraber; } \\
\text { PRETTO, Nelson De Luca }\end{array}$ & 14 & GUATTARI, Félix & 18 \\
\hline $\begin{array}{l}\text { CASTELLS, Manuel; } \\
\text { GUATTARI, Félix; } \\
\text { MARTÍN-BARBERO, Jesús }\end{array}$ & 13 & $\begin{array}{l}\text { MATURANA, Humberto } \\
\text { Ramesin }\end{array}$ & 17 \\
\hline FREIRE, Paulo & 12 & CASTELLS, Manuel & 14 \\
\hline \multirow[t]{2}{*}{ BARTHES, Roland } & 11 & $\begin{array}{l}\text { BARBOSA, Ana Mae; } \\
\text { BAUMAN, Zygmunt }\end{array}$ & 13 \\
\hline & & HABERMAS, Jürgen & 12 \\
\hline $\begin{array}{l}\text { FISCHER, Rosa Ma Bueno; } \\
\text { SOARES, Magda Becker }\end{array}$ & 10 & $\begin{array}{l}\text { LARROSA, Jorge; } \\
\text { SANTAELLA, Lúcia }\end{array}$ & 10 \\
\hline $\begin{array}{l}\text { ADORNO, Theodor W.; } \\
\text { ANDRÉ, Marli; } \\
\text { BONILLA, Mạ Helena S.; } \\
\text { NÓVOA, António }\end{array}$ & 9 & $\begin{array}{l}\text { ADORNO, Theodor W.; } \\
\text { HALL, Stuart; } \\
\text { VARELA, Francisco J. }\end{array}$ & 9 \\
\hline
\end{tabular}




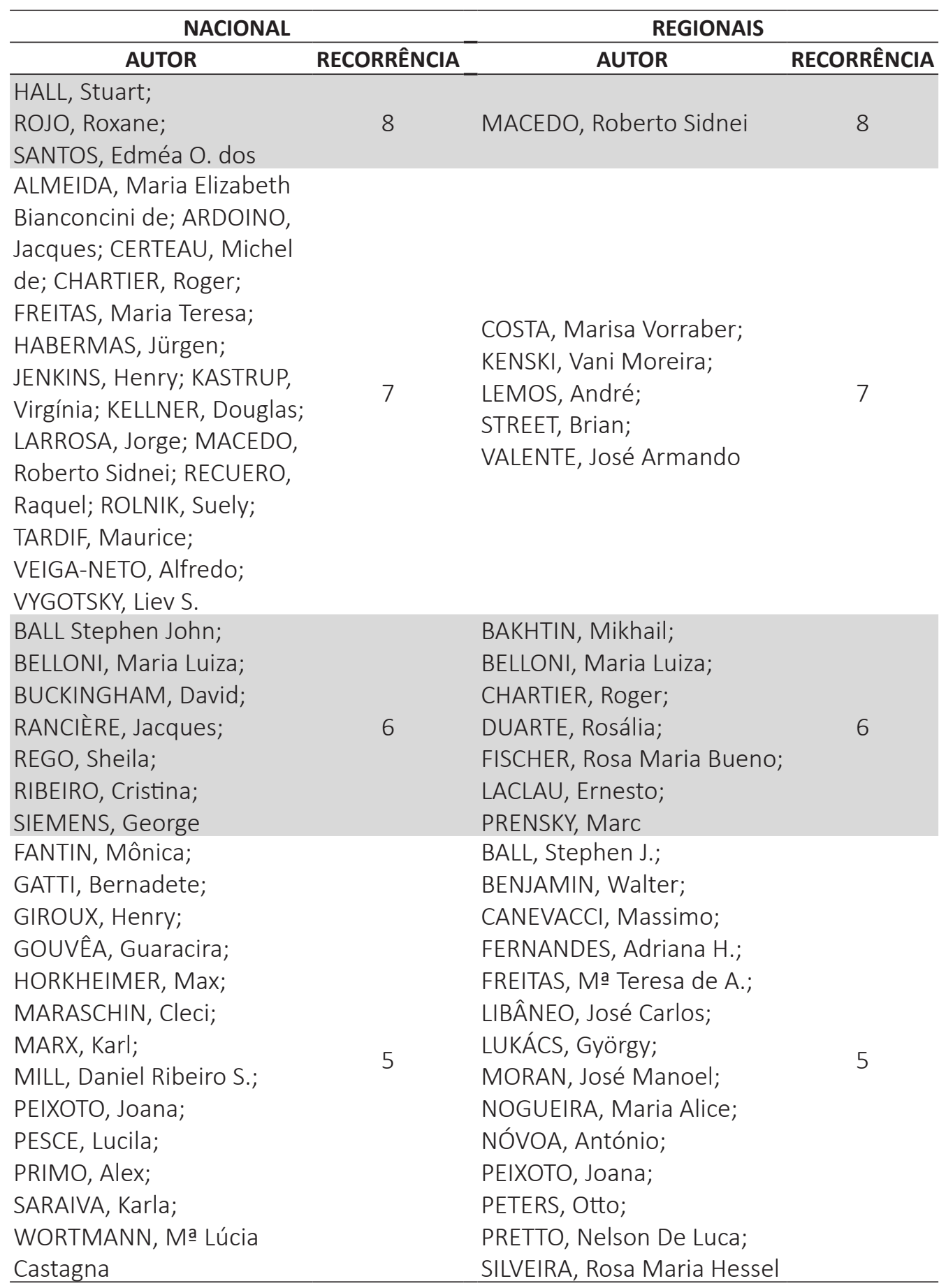

Fonte: Elaborada pelos autores. 
Entre os dez autores mais recorrentes nas duas bases de dados, figuram Pierre Lévy, Gilles Deleuze, Michel Foucault e Félix Guattari, além dos documentos oficiais. Pierre Lévy é o autor mais citado tanto nos trabalhos apresentados nos encontros nacionais quanto em eventos regionais da ANPEd, constituindo-se assim como um importante referencial nas discussões do GT 16. Em situação oposta está Jesús Martín-Barbeiro, que aparece entre os mais citados apenas nos encontros nacionais, não ultrapassando cinco recorrências em nenhum dos eventos regionais, nos quais surge apenas quando se reúnem todas as recorrências de autores citados nos trabalhos apresentados nesses encontros.

Entre os autores com maior recorrência nos trabalhos apresentados nos encontros nacionais, apenas Zygmunt Bauman, Mikhail Bakhtin, Manuel Castells, Lúcia Santaella, Marisa Vorraber Costa e André Lemos são citados com maior frequência em eventos das regiões Sul e/ou Sudeste. Esses dados indicam certa aproximação entre as referências teóricas utilizadas na construção das discussões do GT 16 das regiões Sul e Sudeste e as dos eventos nacionais.

\section{CONSIDERAÇÕES FINAIS}

Fazer um estudo e um levantamento dos principais autores-referência utilizados pelos pesquisadores que apresentam e publicam no GT 16 da ANPEd confirmou ser um exercício profícuo para se analisar as possíveis tendências seguidas por eles, assim como para detectar a necessidade de aprofundamento ou inovação na área. Concluída a análise, é possível apontar alguns elementos importantes dessas publicações, a saber:

a) A existência de uma grande inserção de referências a Pierre Lévy, Manuel Castells, Zygmunt Bauman, Michel Foucault, Félix Guattari, Lúcia Santaella, Maria Elizabeth Almeida e Rosa Maria Fischer como referencial teórico do GT 16 da ANPEd, seja nas reuniões nacionais, seja nas regionais. No campo da Educação, o autor-referência mais citado foi Paulo Freire, mas outros autores também tiveram forte presença, a saber: Gilles Deleuze, Theodor Adorno e Edgar Morin. Os dados indicam a continuidade da tendência de se utilizar os mesmos autores-referências identificados por Mostafa e Máximo em sua obra de 2003, o que coloca em debate a necessidade, ou não, de novos enfoques ${ }^{6}$ ou inovações na área. Nesse

\footnotetext{
${ }^{6}$ Sobre essa questão, Sossai, Grimm e Loureiro (2016), afirmam que as associações que têm como fim a difusão do saber científico engendram cobiçados espaços de poder que demarcam epistemologicamente saberes específicos.
} 
sentido, os dados e análises aqui apresentados nos conduzem à seguinte problematização: a utilização dos mesmos autores-referência ou, ainda, a frequência dos mesmos pesquisadores no GT 16 da ANPEd é uma tendência induzida nos trabalhos aprovados?

b) A forte presença de documentos legais, normativos e de regulamentação do governo, o que se configura como um dos aspectos mais representativos em ambas as reuniões (regionais e nacionais).

c) A tendência de utilizar, nos trabalhos regionais, pesquisadores que possuem vinculação com essas mesmas regiões, sobretudo as do Sul e Sudeste. Esse fato pode ser indicativo de um mesmo eixo teórico entre os grupos de pesquisa/ estudo dessas regiões, assim como um maior fluxo e intercâmbio de suas produções e posicionamento teórico.

d) A forma de se estabelecer o vínculo dos autores dos trabalhos é problemática, e, nesse sentido, um dado chamou a atenção: não houve nenhum trabalho com vínculo com a região Norte publicado nos Anais das reuniões nacionais no GT 16.

e) A maior incidência de autores vinculados à Comunicação, em detrimento da área da Educação, o que deixa demarcada uma perspectiva para ser problematizada no GT 16.

Como os autores deste artigo são pesquisadores vinculados ao GT 16, é importante ressaltar que, desde uma perspectiva interna dos trabalhos desse grupo, é possível problematizar e perceber os demais autores e as tendências, ficando, porém, o alerta para que se estabeleça um debate sobre a relação entre os eventos nacionais e regionais, considerando-se a quantidade de trabalhos/ autores, bem como a distribuição deles. A emergência de redes de pesquisa e a cooperação entre diferentes grupos de distintas regiões talvez pudessem minimizar as concentrações antes mencionadas, de modo a enriquecer a pesquisa e o debate no GT 16.

Trabalhar a relação entre educação e comunicação em tempos de cultura digital é um desafio aberto a todos/as que atuam no campo educativo, enquanto a regionalização da produção acadêmica é importante para que se compreendam os diferentes contextos de um país continental como o Brasil. Isso, no entanto, seria enriquecido estabelecendo-se conexões entre as produções regionais e o contexto nacional, o que poderia engendrar novas possibilidades de pesquisas, 
conhecimentos e compreensões sobre a temática. Essa é, sem dúvida, uma das uma das contribuições que levantamentos como este podem oferecer.

\section{REFERÊNCIAS}

BUFREM, Leilah Santiago.; FREITAS, Juliana Lazzarotto.; NASCIMENTO, Bruna Silva. Autoria e pesquisa em Organização do Conhecimento: análise da produção científica em Ciência da Informação. Em Questão, Porto Alegre, v. 20, n. 3, p. 150-65, edição especial, 2014.

BUFREM, Leilah Santiago; PRATES, Yara. O saber científico registrado e as práticas de mensuração da informação. Ciência da Informação, Brasília, v. 34, n. 2, p. 9-25, maio/ ago. 2005.

FIGUEIREDO, Nice. Da importância dos artigos de revisão da literatura. Revista Brasileira de Biblioteconomia e Documentação, São Paulo, v. 23, n. 1/4, p. 131-5, jan./dez. 1990.

LIBÂNEO, José Carlos. Perspectivas de uma pedagogia emancipadora face às transformações do mundo contemporâneo. Pensar a Prática, Goiânia, v. 1, p. 1-22, dez. 1997. Entrevista concedida ao Prof. Nivaldo A. N. David. Disponível em: https://www. revistas.ufg.br/fef/article/view/8/7. Acesso em: 26 mar. 2019.

MORAES, Moema Gomes. Pesquisas sobre educação e tecnologias: questões emergentes e configuração de uma temática. 2016. 159 f. Tese (Doutorado em Educação)- Pontifícia Universidade Católica de Goiás, Goiânia, 2016.

MOSTAFA, Solange Puntel; MÁXIMO, Luis Fernando. A produção científica da Anped e da Intercom no GT da Educação e Comunicação. Ciência da Informação, Brasília, v. 2, n. 1, p. 96-101, jan./abr. 2003. Disponível em: http://www.scielo.br/pdf/ci/v32n1/15977. pdf. Acesso em: 10 fev. 2019.

SIDONE, Otávio José Guerci; HADDAD, Eduardo Amaral; MENA-CHALCO, Jesús. A ciência nas regiões brasileiras: evolução da produção e das redes de colaboração científica. Revista TransInformação, Campinas, SP, v. 28, n. 1, p. 1-25, jan./abr. 2016. Disponível em: http://www.scielo.br/pdf/tinf/v28n1/0103-3786-tinf-28-01-00015.pdf. Acesso em: 21 maio 2019.

SOARES, Patrícia Bourguignon; CARNEIRO, Teresa Cristina Janes; CALMON, João Luiz; CASTRO, Luiz Otávio da Cruz de Oliveira. Análise bibliométrica da produção científica brasileira sobre Tecnologia de Construção e Edificações na base de dados Web of Science. Ambiente Construído, Porto Alegre, v. 16, n. 1, p. 175-85, jan./mar. 2016. 
SOSSAI, Fernando Cesar; GRIMM, Viviane; LOUREIRO, Carla Cristiane. Escritos sobre tecnologias e políticas educacionais no Brasil: uma análise dos trabalhos publicados pela Anped e RBPAE (2000-2013). Revista Latinoamericana de Tecnología Educativa [online], v. 15, n. 3, p. 39-54, 2016. Disponível em: https://relatec.unex.es/article/view/2245. Acesso em: 18 fev. 2019.

VOSGERAU, Dilmeire Sant'Anna Ramos; ROMANOWSKI, Joana Paulin. Estudos de revisão: implicações conceituais e metodológicas. Revista Diálogo Educacional, Curitiba, v. 14, n. 474, p. 165-89, jan./abr. 2014.

\section{Sobre os autores:}

Jhonny David Echalar: Professor efetivo da Secretaria de Estado da Educação de Goiás, doutorando em Educação pelo PPGE FE/UFG. Integrante do Grupo de Estudos e Pesquisas em Educação a Distância-GEaD e do Kadjót. E-mail: jhonnyechalar@gmail.com, Orcid: http://orcid.org/0000-0002-4056-2804

Daniela da Costa Britto Pereira Lima: Professora Adjunta da Universidade Federal de Goiás no Curso de Pedagogia e Professora do Programa de Pós-Graduação em Educação (PPGE/UFG). Editora Chefe da Revista UFG, membro do conselho editorial da Revista Brasileira de Política e Administração da Educação (RBPAE), membro do Conselho Editorial da Revista Revelli (UEG), da Revista Exitus (UFOPA) e da Revista Série-Estudos da UCDB. Líder do Grupo de Pesquisa em Tecnologias e Educação a Distância (GEaD/UFG/DGP-CNPq). E-mail: daniela_lima@ufg.br, Orcid: http://orcid.org/0000-0002-1075-2113

Kátia Morosov Alonso: Professora associada da Universidade Federal de Mato Grosso (UFMT). Docente do Programa de Pós-Graduação em Educação- PPGE do Instituto de Educação da UFMT. Líder do Grupo de Pesquisa Laboratório de Estudos Sobre Tecnologias da Informação e Comunicação na Educação- LêTECE.

E-mail: katia.ufmt@gmail.com, Orcid: http://orcid.org/0000-0002-7125-664X

\section{Recebido em março de 2019 Aprovado em agosto de 2019}


